\title{
1 Higher fish consumption and lower risk of central nervous system demyelination
}

2 Lucinda J Black ${ }^{1}$, Yun Zhao ${ }^{1}$, Yee Cheng Peng ${ }^{1}$, Jill L Sherriff ${ }^{1}$, Robyn M Lucas ${ }^{2,3}$, Ingrid van

3 der $\mathrm{Mei}^{4}$, the Ausimmune Investigator Group, Gavin Pereira ${ }^{1}$

$4 \quad{ }^{1}$ School of Public Health, Curtin University, Bentley, WA 6102, Australia

$5 \quad{ }^{2}$ National Centre for Epidemiology and Population Health, The Australian National

6 University, Canberra, ACT 1200, Australia

$7 \quad{ }^{3}$ Centre for Ophthalmology and Visual Science, University of Western Australia, Perth, WA

8 6009, Australia

$9{ }^{4}$ Menzies Institute for Medical Research, University of Tasmania, Hobart, Tasmania,

10 Australia

\section{Correspondence:}

14 Lucinda Black, School of Public Health, Curtin University, Kent Street, Bentley, Western,

15 Australia 6102, Australia

16 Phone: 089266 2523; Email: lucinda.black@curtin.edu.au

17

18 Running Title: Fish consumption and multiple sclerosis 
Abstract

21 Background/Objectives: The evidence for diet as a risk factor for multiple sclerosis (MS) is

22 inconclusive. We examined the associations between fish consumption and risk of a first

23 clinical diagnosis of central nervous system demyelination (FCD), a common precursor to

24 MS.

25 Methods: The 2003-2006 Ausimmune Study was a case-control study examining

26 environmental risk factors for FCD, with participants recruited from four regions of Australia

27 and matched on age, sex and study region. Dietary intake data were collected using a food

28 frequency questionnaire. We used conditional logistic regression models to test associations

29 between fish consumption (total, tinned, grilled, and fried) and risk of FCD ( 249 cases, 438

30 controls), adjusting for history of infectious mononucleosis, smoking, serum 25-

31 hydroxyvitamin D concentrations, socioeconomic status, omega-3 supplement use, dietary

32 under-reporting, and total energy intake.

33 Results: Higher total fish consumption (per $30 \mathrm{~g} /$ day, equivalent to two serves/week) was

34 associated with a $18 \%$ reduced risk of FCD (AOR $0.82 ; 95 \% \mathrm{CI} 0.70,0.97)$. While we found

35 no statistically significant associations between grilled and fried fish consumption and risk of

36 FCD, higher tinned fish consumption (per $30 \mathrm{~g} /$ day) was associated with a $41 \%$ reduced risk

37 of FCD (AOR 0.59; 95\% CI 0.39, 0.89).

38 Conclusions: Tinned fish is predominantly oily, whereas grilled and fried fish are likely to be

39 a combination of oily and white types. Oily fish is high in vitamin D and very long chain

40 polyunsaturated omega-3 fatty acids, both of which may be beneficial in relation to MS. 
47 Multiple sclerosis (MS) is a chronic inflammatory and neurodegenerative disease of the central nervous system (CNS) characterised by demyelination and episodes of neurological

49 disability or progressive neurologic deterioration [1]. The disease affects more than two

50 million people globally, and is two to three times more common in females than males. A number of genetic and environmental risk factors have been described, the latter including past history of infectious mononucleosis, adolescent obesity, low past sun exposure, smoking, and low vitamin D status [1]. By the time of peak MS risk - early to middle adulthood - very few of these risk factors are modifiable [2]. There is, however, some evidence to indicate that diet is a potentially modifiable risk factor for MS [3-9].

A number of studies have shown that oily fish consumption associates with reduced risk of MS $[8,10,11]$. Oily fish is the best natural source of both dietary vitamin D [12] and very long-chain omega-3 polyunsaturated fatty acids (VLCn3PUFAs) [13], both of which may have a beneficial role in MS. The association between vitamin D status and risk of MS is well-established [2], while VLCn3PUFAs - namely eicosapentaenoic acid (EPA), docosahexaenoic acid (DHA), and docosapentaenoic acid (DPA) - play critical roles in the central nervous system, exhibiting anti-inflammatory and neuro-protective effects [14].

The 2003-2006 Australian Multi-centre Study of Environment and Immune Function (the Ausimmune Study) [15] is a multicentre, incident case-control study investigating the environmental risk factors for a first clinical diagnosis of CNS demyelination (FCD), a common precursor to MS. The Ausimmune Study is one of the largest, most wellcharacterised samples of people with early MS worldwide. Previously, higher vitamin D 
status [16], higher VLCn3PUFA intakes (largely from fish, but also including small amounts

71 from commonly-consumed meats, such as beef and ham) [17], a higher healthy dietary

72 pattern score [9], and higher unprocessed red meat consumption [18] have been associated with reduced risk of FCD in the Ausimmune Study. We build on these studies by examining the associations between fish consumption and risk of FCD using data from the Ausimmune

75 Study.

\section{Methods}

\section{Study population}

80 Between November 2003 and December 2006, participants were recruited from four regions of Australia: Brisbane city, Newcastle region, Geelong and the Western districts of Victoria, and the island of Tasmania [15]. Case participants ( $n=282 ; 18-59$ years) were referred to the study as previously described [15]. Following a full history and neurological examination, a study neurologist confirmed the date of onset and presenting symptoms suggestive of CNS demyelination [15]. Within the study period, case participants were diagnosed with CNS demyelination for the first time. The diagnoses included: a classic first demyelinating event

87 (FDE; defined as a single, first, episode of clinical symptoms suggestive of CNS demyelination; $n=216$ ); a first recognised event, but past history revealed a prior, undiagnosed event, that, on review was highly suggestive of CNS demyelination $(n=48)$; first

90 presentation of primary progressive MS (based on neurological assessment on study entry $(n=18))$. It is unlikely that a prior unrecognised demyelinating event that had not been ascribed to CNS demyelination would have triggered any changes in dietary behaviour; thus

93 these participants are considered to have an 'incident' FCD. The date of MRI scan, which

94 was available for most participants, was use as a proxy for the date of FCD. There was a time 
95 lag between the date of MRI scan by the neurologist (the date of the diagnosis which brought

96 the participants into the study) and the study interview. For participants with dietary intake

97 data, the median (interquartile range (IQR)) time lag was 101 (147) days.

98

99 The Australian Electoral Roll (compulsory registration for citizens $\geq 18$ years) was used to

100 randomly select control participants $(n=558)$ from the general population. Control

101 participants were matched to case participants on age (within two years), sex and study

102 region. Between one and four controls were matched to each case to maximise power, with

103 more controls per case in regions with a lower expected number of cases due to being either

104 at lower latitude (and lower expected incidence) or a smaller source population. Ethics

105 approval was obtained from the nine Human Research Ethics Committees of the participating

106 institutions [15]. All participants gave written informed consent for the use of their data. All

107 participant information was anonymised and de-identified prior to analysis.

108

109 Dietary assessment

110 Information on habitual dietary intakes in the 12 months prior to the study interview was

111 collected using the Cancer Council Victoria Dietary Questionnaire for Epidemiological

112 Studies version 2 (DQESv2) [19]. The DQES v2 is a self-administered, semi-quantitative,

113 food frequency questionnaire (FFQ) developed for use in the ethnically-diverse adult

114 Australian population [20]. The consumption of food items from four food groups (cereals,

115 sweets and snacks; dairy, meats and fish; fruit; vegetables) was recorded on a scale from

116 "never" to "three or more times per day". Portion size diagrams of four commonly consumed

117 foods (potato, other vegetables, steak, casserole) were used to determine respondents'

118 average portion size factor, and responses were used to scale standard portion sizes up or 
119 down for different foods [19]. Fish consumption (g/day) was reported for total (sum of

120 tinned, grilled and fried fish), tinned, grilled and fried fish.

122 Covariates

123 Self-reported questionnaires were used to collect information on history of infectious

124 mononucleosis (yes, no and don't know), highest level of education (year 10 or less, year 12

125 and Technical and Further Education, university), total number of years smoked minus any

126 periods of absence. Socioeconomic status was assessed as quintiles of the Index of Relative

127 Socio-economic Advantage and Disadvantage (IRSAD) using postal area code and data from

128 the 2006 Census of Population and Housing: Socio-Economic Indexes for Areas (SEIFA),

129 Australia [21]. IRSAD summarises information about the economic and social conditions of

130 households within an area, including relative advantage and disadvantage measures: a low

131 score indicates relatively greater disadvantage; a high score indicates greater advantage in

132 general [21]. Supplement use was captured, as follows: "In the last 12 months, have you used

133 any dietary or vitamin supplements on a regular basis?”. If yes, participants recorded the

134 name, type, dose and frequency of use. Those who were using any fish oil, omega-3 or cod

135 liver oil supplements were considered to be using an omega-3 supplement.

136

137 A study nurse measured stature and weight. Basal metabolic rate (BMR) was calculated using

138 the equations developed by Harris and Benedict [22]. Under-reporters were classified using a

139 Goldberg cut-off below BMRx1.05 [23] and a two-category variable was defined: under-

140 reporter $v s$. plausible reporter. Most participants (94\%) provided a blood sample: serum

141 aliquots $(1 \mathrm{~mL})$ were stored at $-80^{\circ} \mathrm{C}$. Serum samples were analysed at study completion for

142 25-hydroxyvitamin $\mathrm{D}(25(\mathrm{OH}) \mathrm{D})$ concentrations using liquid chromatography tandem mass

143 spectrometry [16]. Using the seasonal patterns, serum $25(\mathrm{OH}) \mathrm{D}$ concentrations for control 
144 participants were adjusted to match the date of the case blood draw [16]. This was done to

145 account for blood samples of cases and controls being taken at different times of the year.

146

147 Statistical analysis

148 Characteristics of participants were described as frequency and percentage for categorical

149 variables, mean and standard deviation (SD) for continuous variables with a Normal

150 distribution, and median and interquartile range (IQR) for continuous variables with a non-

151 Normal distribution.

152 We used conditional logistic regression models (with cases and controls matched on age, sex 153 and study region) to estimate odds ratios (ORs), 95\% confidence intervals (95\% CI) and $p$

154 values for associations between fish consumption (total, tinned, grilled and fried) and risk of

155 FCD. Fish consumption was analysed as a continuous variable per $30 \mathrm{~g} / \mathrm{day}$, to reflect a

156 clinically relevant level of consumption (equivalent to approximately two serves/week).

157 Model 1 was unadjusted; model 2 was adjusted for known environmental risk factors for MS

158 (history of infectious mononucleosis, serum 25(OH)D concentrations, total years of

159 smoking), along with socioeconomic status, omega-3 supplement use, dietary under-reporting

160 and total energy intake.

161

162 We tested for non-linearity using quadratic terms for total, tinned, grilled and fried fish 163 consumption. To test for any sex differences, we included an interaction term for fish

164 consumption and sex in the adjusted models. We conducted the following sensitivity

165 analyses: a) within the smaller group of those with a classic FDE; and b) including only

166 participants with plausible energy intakes (500-5000 kcal/day, based on a daily energy intake 
associated with survival [23], which excludes those with extreme energy intakes as previously described $[24,25])$.

169

170 The Paramed command in Stata [26] was used to assess the potential mediating effects

171 (natural indirect effect, NIE) of serum 25(OH)D concentrations on the relationship between

172 fish consumption and risk of FCD, adjusting for the same environmental risk factors.

173 Statistically, the NIE compares the risks of FCD when the values of the serum $25(\mathrm{OH}) \mathrm{D}$

174 concentrations vary from the one realised at fish consumption $\geq 30 \mathrm{~g} /$ day to the one realised

175 at fish consumption $<30 \mathrm{~g} /$ day, assuming all relevant participants with fish consumption $\geq 30$

$176 \mathrm{~g} /$ day. The mediation analyses were performed for all participants, and further for the subgroup of people who had plausible energy intakes. Data were analysed using Stata 14 software [27].

\section{$180 \quad$ Results}

181

182 A total of 791 participants (272 cases, 519 controls) provided dietary intake data. Missing 183 data for covariates were as follows: total years of smoking $n=3$; serum $25(\mathrm{OH}) \mathrm{D}$

184 concentrations, $n=38$; dietary misreporting, $n=3$; socioeconomic status, $n=10$. A total of 687

185 participants (249 cases, 438 controls) provided complete data on dietary intake and all

186 covariates, and were part of at least a matched control pair. As expected, case participants

187 were more likely than controls to have a history of infectious mononucleosis, lower serum $18825(\mathrm{OH}) \mathrm{D}$ concentrations, and a greater total number of years of smoking (Table 1). Median 189 total, tinned and grilled fish consumption were lower in case than control participants, while 190 fried fish consumption was higher. Total fish consumption $\geq 30 \mathrm{~g} /$ day was reported by $40 \%$ of 
191 participants $(10,12$ and $3 \%$ of participants consumed $\geq 30 \mathrm{~g} /$ day tinned, grilled and fried fish,

192 respectively).

193

194 In adjusted models, higher total fish consumption (per $30 \mathrm{~g} /$ day, equivalent to two

195 serves/week) was associated with a $18 \%$ reduced risk of FCD, and higher tinned fish

196 consumption (per $30 \mathrm{~g} /$ day) was associated with a 41\% reduced risk of FCD (Table 2). There

197 were no statistically significant associations between grilled or fried fish consumption and

198 risk of FCD (Table 2). The effect estimates for all models were similar when limited to those

199 with plausible energy intakes and in the smaller subgroup of those with a classic FDE (Table

200 2). There was no evidence of non-linearity in any models and no evidence of any interactions

201 between fish consumption and sex. We found no evidence of statistically significant

202 mediating effects of the serum $25(\mathrm{OH}) \mathrm{D}$ concentrations (total fish intake: $\mathrm{NIE}=1.00,95 \% \mathrm{CI}$ :

203 0.94-1.05, $\mathrm{p}=0.846$; tinned fish intake: $\mathrm{NIE}=0.99,95 \% \mathrm{CI} 0.89-1.09, \mathrm{p}=0.808)$. The results

204 were similar for the subgroup of people who had plausible energy intakes (total fish intake:

$205 \mathrm{NIE}=1.00,95 \% \mathrm{CI}: 0.95-1.05, \mathrm{p}=0.941$; tinned fish intake: $\mathrm{NIE}=1.00,95 \% \mathrm{CI}: 0.92-1.08$, $206 \mathrm{p}=0.918)$.

207

208 Discussion

209

210 Our results demonstrate an association between higher fish consumption and lower risk of

211 FCD, particularly for tinned fish. An increment of two serves/week of tinned fish associated

212 with approximately $40 \%$ reduced risk of FCD. Two serves of fish per week is in line with the

213 Australian Dietary Guidelines (one serve $=100 \mathrm{~g}$ cooked fish fillet ( $115 \mathrm{~g} \mathrm{raw}$ ) or one small

214 can of fish) [28]. Tinned fish is primarily oily fish (e.g. tuna, salmon, sardines, mackerel),

215 which is the richest dietary source of both vitamin D [12] and VLCn3PUFAs [13]. We found 
no association between consumption of grilled or fried fish and risk of FCD. Grilled fish is

217 likely to include a combination of oily and white fish. The latter has lower levels of both

218 vitamin D and VLCn3PUFAs than oily fish. Fried fish, particularly from take-away outlets, is

219 likely to be white fish, again with lower levels of both vitamin D and VLCn3PUFAs than oily 220 fish.

Low vitamin D status is a known risk factor for MS [16]. The major source of vitamin D for humans is cutaneous synthesis from sun exposure; dietary intake of vitamin D becomes important when sun exposure is limited, with oily fish considered one of the best natural sources. However, in this study, we have not been able to demonstrate that serum $25(\mathrm{OH}) \mathrm{D}$ concentration is a significant mediator on the relationship between the fish consumption and the risk of FCD. This contradicts a previous hypothesis that intake of oily fish may compensate for vitamin D deficiency that is associated with increased MS risk [8].

230 VLCn3PUFAs have been shown to suppress pro-inflammatory T-helper cells [29]; to inhibit

231 the migration of T-helper cells across the blood brain barrier [30]; and to inhibit matrix metalloproteinases which are toxic to myelin [31]. DHA is a major constituent of neuronal membranes [32] and appears to play a role in synaptic signal transduction [33], while DPA is emerging as an important bioactive fatty acid, with a role in brain function and mental health

235 [34]. Previous analysis of data from the Ausimmune Study showed a reduced risk of FCD

236 with increasing intake of VLCn3PUFAs [17]. Furthermore, a small number of clinical trials 237 have investigated the hypothesis that a higher intake of omega-3 fatty acids reduces disease 238 activity in those with clinically diagnosed MS; however, the evidence is inconclusive [35239 37]. We were not able to test the mediating effects of VLCn3PUFAs due to the high uptake 
of fish oil supplements after FCD and the strong possibility of reverse causation in measuring

241 VLCn3PUFAs in blood after diagnosis.

242

243 Fish is also an important source of the sulfur-containing amino acid, taurine [38-40], which

244 has therapeutic potential against neurological disorders [41]. Taurine has been shown to have anti-inflammatory and neuroprotective properties in a mouse Parkinson's disease model [42], and has been identified as a dysregulated metabolite in animal models of MS, including in non-human primates [43]. Using a global metabolomics approach, taurine has also been shown to enhance remyelination through increasing differentiation of oligodendrocyte precursor cells. On the basis of these findings, the authors suggested that taurine supplementation, in combination with existing treatment strategies, could be a feasible strategy to improve remyelination [44]. To our knowledge, the role of taurine in MS risk has not been investigated.

Our results concur with the few other studies investigating fish consumption and risk of MS. In a 2005-2012 population-based case-control study (1879 cases, 4135 controls) of incident MS in Sweden, participants were asked to specify how often, on average, they had eaten oily or white fish during the last five years [8]. Consumption of oily, but not white, fish was associated with decreased occurrence of MS. A case-control study conducted in Norway in 2003 (152 cases, 402 controls) investigated sun exposure and dietary vitamin D in people with MS residing at latitudes above the Arctic Circle [10]. The results supported a protective effect of consuming boiled or fried fish (unspecified type) three or more times a week. In a case-control study of incident MS (197 cases, 202 age- and sex-matched controls) conducted between 1992 and 1995 in Montreal, Canada, dietary intake data were collected using a 164-

264 item food frequency questionnaire [11]. Fish consumption was protective in women only, 
with borderline statistical significance; however, the type of fish consumed was unspecified and likely to reflect consumption of both oily and white fish.

268 A major strength of the Ausimmune Study is its strong study design (multicentre, matched case-control), along with the recruitment of participants with an incident FCD (rather than participants with established MS). Although not all participants had a classic FDE during the study period, we performed sensitivity analyses in the smaller group of those with a classic FDE. Results were similar to the main models, albeit with wider confidence intervals. We used an established food frequency questionnaire to collect information on dietary intake over the previous 12 months, and we were able to account for a number of important potential confounders, including serum $25(\mathrm{OH}) \mathrm{D}$ concentrations measured by an accurate and reliable methodology [45].

Although the widely-acknowledged under-reporting of energy intake [46] is a limitation of our study, we attempted to account for dietary under-reporting by adjusting for a misreporting variable. Further, we performed a sensitivity analysis including only participants with plausible energy intakes (500-5000 kcal/day), with minimal change in effect estimates compared with the main model. Although case participants may be more likely to recall exposure to risk factors than control participants [47], this bias is likely to be minimal in our study because diet is not commonly considered a cause of CNS demyelination. The association between higher fish consumption and reduced risk of FCD in our study may be due to lifestyle or environmental characteristics not captured in our analyses, and we cannot rule out the possibility of residual confounding. However, we adjusted for the main known environmental risk factors for MS. Other lifestyle characteristics, including current body mass index and physical activity, were not associated with risk of FCD in previous analysis 
of the Ausimmune Study [48]. Since the study consisted of Australian participants who were

291 predominantly Caucasian, the findings may not be generalisable to other populations with

292 differing diets.

293

294 Our results suggest a protective effect of higher fish consumption, particularly tinned (oily)

295 fish consumption, on risk of FCD. The equivalent of two serves per week of tinned fish was

296 associated with approximately $40 \%$ reduced risk of FCD. This level of fish consumption is in

297 line with the Australian Dietary Guidelines. Given the higher levels of VLCn3PUFAs in oily

298 fish compared with white fish, future studies would benefit from separating the consumption

299 of these two types of fish.

300

301 Acknowledgements

302 We thank the participants of the Ausimmune Study.

304 We would like to acknowledge and thank the physicians who notified case participants to the

305 Ausimmune Study:

306 Jeffrey Blackie FRACP, Richard Bourke FRACGP, John Cameron MD, Ross Carne MD,

307 Ben Clark FRANZCO, Steven Collins MD, Diana Conrad FRANZCO, Michael Coroneos

308 FRACS, Nicholas Downie FRANZCO, David Floate FRACP, Peter Gates FRACP, Kerryn

309 Green FRACP, Erwin Groeneveld FRANZCO, John Harrison FRANZCO, Michael Haybittel

310 FRANZCO, Robert Henderson FRACP, John Henshaw MMed, James Hurley MD, Dean

311 Jones FRACP, Michael Katekar MBBS, Anthony Kemp FRACP, Mark King FRACP,

312 George Kiroff FRACS, Brett Knight FRACP, Thomas Kraemer FRACP, Cecile Lander

313 FRACP, Jeannette Lechner-Scott FRACP, Andre Loiselle FRACP, Paul McCartney

314 FRANZCO, Pamela McCombe PhD, Mark McGree FRANZCO, David McKnight 
315 FRANZCO, Daniel McLaughlin PhD, Satish Nagarajah MBBS, Rob Nightingale FRACP,

316 ,Terence O’Brien MD, John O'Sullivan MD, Gregory Outteridge FRANZCO, Anthony Pane

317 FRANZCO, Mark Parsons FRACP, Melinda Pascoe FRACP, David Prentice PhD, Richard

318 Ralph FRACGP, Stephen Read FRACP, John Richmond FRACP, Ian Routley FRANZCO,

319 Timothy Ruddle FRANZCO, Noel Saines FRACP, Stan Siejka MBBS (dec), Christopher

320 Staples FRACP, Paul Talman FRACP, Don Todman FRACP, Nitin Verma FRANZCO,

321 Brendan Vote FRANZCO, Michael Waldie FRANZCO, Michael Weetch FRACP, Rodney

322 Westmore FRANZCO, Andrew Wong FRACP;

323 and the local research officers:

324 Susan Agland BN, Barbara Alexander BN, Marcia Davis MD, Zoe Dunlop BN, Rosalie Scott

325 BN, Marie Steele RN, Catherine Turner MPH\&TM, Brenda Wood RN;

326 and the Ausimmune Study project officers during the course of the study:

327 Jane Gresham MA(Int Law), Camilla Jozwick BSc(Hons), Helen Rodgers RN.

328

329 The Ausimmune Investigator Group includes the following investigators:

330 Dr Caron Chapman, Barwon Health, Geelong, Victoria, Australia

331 Prof Alan Coulthard, Royal Brisbane and Women's Hospital and The University of

332 Queensland, Brisbane, Queensland, Australia

333 Prof Keith Dear, School of Public Health, University of Adelaide, South Australia,

334 Australia

335 Prof Terry Dwyer, Murdoch Childrens Research Institute, University of Melbourne,

336 Melbourne, Victoria, Australia

337 Prof Trevor Kilpatrick, Centre for Neuroscience, University of Melbourne, Melbourne, 338 Australia 
339 Prof Robyn Lucas, National Centre for Epidemiology and Population Health, The

340 Australian National University, Canberra, Australian Capital Territory, Australia

341 Prof Tony McMichael (dec), National Centre for Epidemiology and Population Health, The

342 Australian National University, Canberra, Australian Capital Territory, Australia

343 Prof Michael P Pender, Royal Brisbane and Women's Hospital and The University of

344 Queensland, Brisbane, Queensland, Australia

345 Prof Anne-Louise Ponsonby, Murdoch Childrens Research Institute, University of

346 Melbourne, Melbourne, Victoria, Australia

347 Prof Bruce Taylor, Menzies Institute for Medical Research, University of Tasmania,

348 Hobart, Tasmania, Australia

349 A/Prof Patricia Valery, QIMR Berghofer Medical Research Institute, Brisbane, Queensland, $350 \quad$ Australia

351 Prof Ingrid van der Mei, Menzies Institute for Medical Research, University of Tasmania,

352 Hobart, Tasmania, Australia

353 Dr David Williams, Hunter Health, Newcastle, New South Wales, Australia

\section{Financial support}

356 Funding for the Ausimmune Study was provided by the National Multiple Sclerosis Society

357 of the United States of America, the National Health and Medical Research Council of

358 Australia and Multiple Sclerosis Research Australia. L.J.B. is supported by a Multiple

359 Sclerosis Western Australia Postdoctoral Fellowship and a Curtin University Research

360 Fellowship. R.M.L. is supported by a National Health and Medical Research Council of

361 Australia Senior Research Fellowship. Funding bodies had no role in the design or conduct of

362 the study; collection, management, analysis or intepretation of data; or preparation, review or

363 approval of the manuscript. 
365 Conflict of interest: None

366

367 Authorship

368 The Ausimmune Investigator Group and L.J. B. designed the study; L.J.B. analysed and

369 interpreted the data; Y.C.P contributed to data analysis; G.P. provided statistical support and

370 contributed to data interpretation; L.J.B. wrote the paper; J.S., R.M.L., G.P. and the

371 Ausimmune Investigator Group provided critical revision of the manuscript for important

372 intellectual content; L.J.B. had primary responsibility for the final content. All the authors

373 read and approved the final version of the manuscript.

374 
Table 1. Characteristics of Ausimmune participants included in the current study (249 cases, 438 controls)

\begin{tabular}{|c|c|c|}
\hline & Case & Control \\
\hline \multicolumn{3}{|l|}{ Sex, $n(\%)^{1}$} \\
\hline Male & $63(25.3)$ & $108(24.7)$ \\
\hline Female & $186(74.7)$ & $330(75.3)$ \\
\hline Age (years), mean $(\mathrm{SD})^{1}$ & $38.7(9.7)$ & $40.0(9.6)$ \\
\hline \multicolumn{3}{|l|}{ Study region, $n(\%)^{1}$} \\
\hline Brisbane $\left(27^{\circ} \mathrm{S}\right)$ & $83(33.3)$ & $159(36.3)$ \\
\hline Newcastle $\left(33^{\circ} \mathrm{S}\right)$ & $32(12.9)$ & $65(14.8)$ \\
\hline Geelong $\left(37^{\circ} \mathrm{S}\right)$ & $59(23.7)$ & $108(24.7)$ \\
\hline Tasmania $\left(43^{\circ} \mathrm{S}\right)$ & $75(30.1)$ & $106(24.2)$ \\
\hline \multicolumn{3}{|l|}{ History of infectious mononucleosis, $n(\%)$} \\
\hline No & $163(65.5)$ & $345(78.8)$ \\
\hline Yes & $70(28.1)$ & $71(16.2)$ \\
\hline Don't know & $16(6.4)$ & $22(5.0)$ \\
\hline $\begin{array}{l}\text { Serum } 25(\mathrm{OH}) \mathrm{D} \text { concentrations }(\mathrm{nmol} / \mathrm{L}) \text {, mean } \\
(\mathrm{SD})\end{array}$ & $75.6(29.5)$ & $82.1(30.4)$ \\
\hline Total years of smoking, median (IQR) & $5.7(18.6)$ & $2(14.8)$ \\
\hline \multicolumn{3}{|l|}{ Socioeconomic status, $n(\%)$} \\
\hline Quintile 1 (lowest) & $28(11.2)$ & $57(13.0)$ \\
\hline Quintile 2 & $38(15.3)$ & $49(11.2)$ \\
\hline Quintile 3 & $43(17.3)$ & $103(23.5)$ \\
\hline Quintile 4 & $83(33.3)$ & $136(31.1)$ \\
\hline Quintile 5 (highest) & $57(22.9)$ & $93(21.2)$ \\
\hline Energy intake (kcal/day), median (IQR) & $\begin{array}{l}1658.4 \\
(858.1)\end{array}$ & $\begin{array}{l}1743.9 \\
(894.4)\end{array}$ \\
\hline \multicolumn{3}{|l|}{ Dietary misreporting, $n(\%)$} \\
\hline Under-reporter & $106(42.6)$ & $176(40.2)$ \\
\hline Plausible reporter & $143(57.4)$ & $262(59.8)$ \\
\hline \multicolumn{3}{|l|}{ Fish consumption (g/day), median (IQR) } \\
\hline Total fish & $21.7(28.1)$ & $23.7(30.0)$ \\
\hline Tinned fish & $4.7(10.2)$ & $6.6(13.0)$ \\
\hline Grilled fish & $8.5(14.2)$ & $10.6(16.1)$ \\
\hline Fried fish & $3.5(8.6)$ & $2.9(8.2)$ \\
\hline
\end{tabular}

SD, standard deviation; 25(OH)D, 25-hydroxyvitamin D; IQR, interquartile range 
Table 2. Conditional logistic regression models showing associations between total, tinned, grilled and fried fish consumption and a) risk of FCD (249 cases, 438 controls); b) risk of true FDE (191 cases, 328 controls); c) risk of FCD in those with plausible energy intakes (500-5000 kcal/day) (245 cases, 428 controls)

\begin{tabular}{|c|c|c|c|c|}
\hline & \multicolumn{2}{|c|}{ Model 1: unadjusted } & \multicolumn{2}{|c|}{ 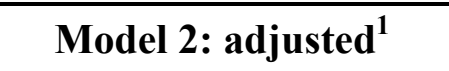 } \\
\hline & OR $(95 \%$ CI $)$ & $P$ & $\operatorname{AOR}(95 \%$ CI) & $\boldsymbol{P}$ \\
\hline \multicolumn{5}{|l|}{ a) risk of $F C D$} \\
\hline Total fish, per $30 \mathrm{~g} /$ day & $0.88(0.76,1.02)$ & 0.088 & $0.82(0.70,0.97)$ & 0.024 \\
\hline Tinned fish, per $30 \mathrm{~g} /$ day & $0.64(0.44,0.94)$ & 0.022 & $0.59(0.39,0.89)$ & 0.012 \\
\hline Grilled fish, per $30 \mathrm{~g} /$ day & $0.89(0.71,1.10)$ & 0.284 & $0.83(0.65,1.07)$ & 0.143 \\
\hline Fried fish, per $30 \mathrm{~g} /$ day & $0.84(0.55,1.28)$ & 0.421 & $0.79(0.49,1.26)$ & 0.321 \\
\hline \multicolumn{5}{|l|}{ b) risk of FDE } \\
\hline Total fish, per $30 \mathrm{~g} /$ day & $0.92(0.79,1.08)$ & 0.295 & $0.89(0.73,1.07)$ & 0.208 \\
\hline Tinned fish, per $30 \mathrm{~g} /$ day & $0.71(0.47,1.09)$ & 0.115 & $0.67(0.42,1.07)$ & 0.096 \\
\hline Grilled fish, per $30 \mathrm{~g} /$ day & $0.92(0.74,1.14)$ & 0.444 & $0.89(0.68,1.16)$ & 0.389 \\
\hline Fried fish, per $30 \mathrm{~g} /$ day & $0.96(0.60,1.53)$ & 0.87 & $0.96(0.55,1.69)$ & 0.898 \\
\hline \multicolumn{5}{|c|}{ c) risk of FCD in those with plausible energy intakes (500-5000 kcal/day) } \\
\hline Total fish, per $30 \mathrm{~g} /$ day & $0.87(0.74,1.02)$ & 0.094 & $0.84(0.70,1.00)$ & 0.054 \\
\hline Tinned fish, per $30 \mathrm{~g} /$ day & $0.66(0.45,0.97)$ & 0.033 & $0.61(0.40,0.93)$ & 0.023 \\
\hline Grilled fish, per $30 \mathrm{~g} /$ day & $0.90(0.69,1.18)$ & 0.461 & $0.88(0.65,1.18)$ & 0.385 \\
\hline Fried fish, per $30 \mathrm{~g} /$ day & $0.82(0.51,1.32)$ & 0.415 & $0.76(0.46,1.28)$ & 0.305 \\
\hline
\end{tabular}


1. Reich DS, Lucchinetti CF, Calabresi PA. Multiple sclerosis. N Engl J Med. 2018; 378: 169-180.

381

382

2. O'Gorman C, Lucas R, Taylor B. Environmental risk factors for multiple sclerosis: a review with a focus on molecular mechanisms. Int J Mol Sci. 2012; 13(9): 1171811752.

3. Lauer K. Notes on the epidemiology of multiple sclerosis, with special reference to

4. Mandia D, Ferraro O, Nosari G, Montomoli C, Zardini E, Bergamaschi R. Res Pub He. 2014; 11(6): 6417.

5. Riccio P, Rossano R. Nutrition facts in multiple sclerosis. ASN Neuro. 2015; 7(1).

6. Jahromi SR, Toghae M, Jahromi MJ, Aloosh M. Dietary pattern and risk of multiple sclerosis. Iran J Neurol. 2012; 11(2): 47-53.

398 7. Sedaghat F, Jessri M, Behrooz M, Mirghotbi M, Rashidkhani B. Mediterranean diet adherence and risk of multiple sclerosis: a case-control study. Asia Pac J Clin Nutr. 2016; 25(2): 377-384.

401 
402 8. Baarnhielm M, Olsson T, Alfredsson L. Fatty fish intake is associated with decreased occurrence of multiple sclerosis. Mult Scler J. 2014; 20(6): 726-732.

404

405

9. Black L, Rowley C, Sherriff J, Pereira G, Ponsonby A-L, Ausimmune Investigator Group et al. A healthy dietary pattern associates with a lower risk of a first clinical diagnosis of central nervous system demyelination. Mult Scler J. 2018: doi:

408 $10.1177 / 1352458518793524$.

409

10. Kampman MT, Wilsgaard T, Mellgren SI. Outdoor activities and diet in childhood and adolescence relate to MS risk above the Arctic Circle. J Neurol. 2007; 254(4): 471477.

11. Ghadirian $\mathrm{P}$, Jain $\mathrm{M}$, Ducic $\mathrm{S}$, Shatenstein $\mathrm{B}$, Morisset R. Nutritional factors in the aetiology of multiple sclerosis: a case-control study in Montreal, Canada. Int J Epidemiol. 1998; 27(5): 845-852.

12. Liu J, Arcot J, Cunningham J, Greenfield H, Hsu J, Padula D et al. New data for vitamin D in Australian foods of animal origin: impact on estimates of national adult vitamin D intakes in 1995 and 2011-13. Asia Pac J Clin Nutr. 2015; 24: 464-471.

13. Meyer BJ. Australians are not meeting the recommended intakes for omega-3 long chain polyunsaturated fatty acids: results of an analysis from the 2011-2012 National Nutrition and Physical Activity Survey. Nutrients. 2016; 8(3): 111. 
14. DeFilippis AP, Sperling LS. Understanding omega-3s. Am Heart J. 2006; 151: 564-570.

427

428

15. Lucas R, Ponsonby AL, McMichael A, van der Mei I, Chapman C, Coulthard A et al. Observational analytic studies in multiple sclerosis: controlling bias through study design and conduct. The Australian Multicentre Study of Environment and Immune Function. Mult Scler J. 2007; 13: 827-839.

16. Lucas RM, Ponsonby A-L, Dear K, Valery PC, Pender MP, Taylor BV et al. Sun exposure and vitamin D are independent risk factors for CNS demyelination. Neurology. 2011; 76(6): 540-548.

17. Hoare S, Lithander F, van der Mei I, Ponsonby AL, Lucas R. Higher intake of omega-3 polyunsaturated fatty acids is associated with a decreased risk of a first clinical diagnosis of central nervous system demyelination: Results from the Ausimmune Study. Mult Scler J. 2016; 22(7): 884-892.

18. Black L, Bowe GS, Pereira G, Lucas RM, Dear K, van der Mei I et al. Higher nonprocessed red meat consumption is associated with a reduced risk of central nervous system demyelination. Front Neurol. 2019; 10: 125.

19. Cancer Council Victoria. Dietary Questionnaire for Epidemiological Studies (DQES v2) User Information Guide: Carlton, 2009. 
20. Ireland P, Jolley D, Giles G, O'Dea K, Powles J, Rutishauser I et al. Development of the Melbourne FFQ: a food frequency questionnaire for use in an Australian prospective study involving an ethnically diverse cohort. Asia Pac J Clin Nutr. 1994; 3(1): 19-31.

21. Australian Bureau of Statistics. Census of Population and Housing, 2006. http://www.abs.gov.au. Accessed 24 January 2019.

22. Harris J, Benedict F. A biometric study of basal metabolism in man, Carnegie Institute of Washington: Washington D.C., 1919.

23. Goldberg GR, Black AE, Jebb SA, Cole TJ, Murgatroyd PR, Coward WA et al. Critical evaluation of energy intake data using fundamental principles of energy physiology: derivation of cut-off limits to identify under-reporting. Eur J Clin Nutr. 1991; 45: 569581.

24. Willett W. Nutritional Epidemiology. In. 3rd ed. New York: Oxford University Press, 2013.

25. Ambrosini GL, Fritschi L, de Klerk NH, Mackerras D, Leavy J. Dietary patterns identified using factor analysis and prostate cancer risk: a case control study in Western Australia. Ann Epidemiol. 2008; 18(5): 364-370. 
26. Emsley R, Liu H. Stata module to perform causal mediation analysis using parametric regression models, 2013. https://ideas.repec.org/c/boc/bocode/s457581.html. Accessed 16 February 2019.

27. StataCorp. 2015. Stata Statistical Software: Release 14. College Station, TX: StataCorp LP

28. Australian Government Department of Health. Lean Meat and poultry, fish, eggs, tofu, nuts and seeds and legumes/beans, 2017.

https://www.eatforhealth.gov.au/food-essentials/five-food-groups/lean-meat-andpoultry-fish-eggs-tofu-nuts-and-seeds-and. Accessed 24 January 2019.

29. Allen MJ, Fan YY, Monk JM, Hou TY, Barhoumi R, McMurray DN et al. n-3 PUFAs reduce T-helper 17 cell differentiation by decreasing responsiveness to interleukin- 6 in isolated mouse splenic CD4(+) T cells. J Nutr. 2014; 144(8): 1306-1313.

30. Shinto L, Marracci G, Bumgarner L, Yadav V. The effects of omega-3 fatty acids on matrix metalloproteinase- 9 production and cell migration in human immune cells: implications for multiple sclerosis. Autoimmune Dis. 2011; 2011: 134592.

31. Liuzzi GM, Latronico T, Rossano R, Viggiani S, Fasano A, Riccio P. Inhibitory effect of polyunsaturated fatty acids on MMP-9 release from microglial cells-implications for complementary multiple sclerosis treatment. Neurochem Res. 2007; 32: 2184-2193. 
32. Yehuda S, Rabinovitz S, Mostofsky DI. Essential fatty acids are mediators of brain biochemistry and cognitive functions. J Neurosci Res. 1999; 56(6): 565-570.

33. Jones CR, Arai T, Rapoport SI. Evidence for the involvement of docosahexaenoic acid in cholinergic stimulated signal transduction at the synapse. Neurochem Res. 1997; 22(6): 663-670.

34. Kaur G, Guo XF, Sinclair AJ. Short update on docosapentaenoic acid: a bioactive longchain n-3 fatty acid. Curr Opin Clin Nutr Metab Care. 2016; 19(2): 88-91.

35. Ramirez-Ramirez V, Macias-Islas MA, Ortiz GG, Pacheco-Moises F, Torres-Sanchez ED, Sorto-Gomez TE et al. Efficacy of fish oil on serum of TNF alpha , IL-1 beta , and IL-6 oxidative stress markers in multiple sclerosis treated with interferon beta-1b. Oxid Med Cell Longev. 2013; 2013: 709493.

36. Bates D, Cartlidge NE, French JM, Jackson MJ, Nightingale S, Shaw DA et al. A doubleblind controlled trial of long chain n-3 polyunsaturated fatty acids in the treatment of multiple sclerosis. J Neurol Neurosurg Psychiatry. 1989; 52(1): 18-22.

37. Torkildsen O, Wergeland S, Bakke S, Beiske AG, Bjerve KS, Hovdal H et al. omega-3 fatty acid treatment in multiple sclerosis (OFAMS Study): a randomized, doubleblind, placebo-controlled trial. Arch Neurol. 2012; 69(8): 1044-1051. 
38. Gormley T, Neumann T, Fagan J, Brunton N. Taurine content of raw and processed fish fillets/portions. Eur Food Res Technol. 2007; 225(5): 837-842.

39. Tørris C, Småstuen MC, Molin M. Nutrients in fish and possible associations with cardiovascular disease risk factors in metabolic syndrome. Nutrients. 2018; 10(7): E952.

40. Wójcik OP, Koenig KL, Zeleniuch-Jacquotte A, Costa M, Chen Y. The potential protective effects of taurine on coronary heart disease. Atherosclerosis. 2010; 208(1): 19-25.

41. Jakaria M, Azam S, Haque ME, Jo S-H, Uddin MS, Kim I-S et al. Taurine and its analogs in neurological disorders: Focus on therapeutic potential and molecular mechanisms. Redox Biol. 2019; 24: 101223.

42. Che Y, Hou L, Sun F, Zhang C, Liu X, Piao F et al. Taurine protects dopaminergic neurons in a mouse Parkinson's disease model through inhibition of microglial M1 polarization. Cell Death Dis. 2018; 9(4): 435-435.

43. 't Hart BA, Vogels JTWE, Spijksma G, Brok HPM, Polman C, van Der Greef J. 1H-NMR spectroscopy combined with pattern recognition analysis reveals characteristic chemical patterns in urines of MS patients and non-human primates with MS-like disease. J Neurol Sci. 2003; 212(1): 21-30. 
44. Beyer BA, Fang M, Sadrian B, Montenegro-Burke JR, Plaisted WC, Kok BPC et al. Metabolomics-based discovery of a metabolite that enhances oligodendrocyte maturation. Nat Chem Biol. 2017; 14(1): 22-31.

45. Black $\amalg$, Anderson D, Clarke MW, Ponsonby A-L, Lucas RM, Ausimmune Investigator Group. Analytical bias in the measurement of serum 25-hydroxyvitamin D concentrations impairs assessment of vitamin D status in clinical and research settings. PLoS ONE. 2015; 10(8): e0135478.

46. Black AE, Prentice AM, Goldberg GR, Jebb SA, Bingham SA, Livingstone MBE et al. Measurements of total energy expenditure provide insights into the validity of dietary measurements of energy intake. J Am Diet Assoc. 1993; 93: 572-579.

47. Althubaiti A. Information bias in health research: definition, pitfalls, and adjustment methods. J Multidiscip Healthc. 2016; 9: 211-217.

48. Ponsonby AL, Lucas RM, Dear K, van der Mei I, Taylor B, Chapman C et al. The physical anthropometry, lifestyle habits and blood pressure of people presenting with a first clinical demyelinating event compared to controls: the Ausimmune study. Mult Scler J. 2013; 19(13): 1717-1725. 